\title{
Sistemas de tutoramento e épocas de transplante de physalis
}

\author{
Periods replanting and training systems of cape-gooseberry
}

\section{Cláudia Simone Madruga Lima ${ }^{\mathrm{I} *}$ Michel Aldrighi Gonçalves $^{\mathrm{I}}$ Zeni Fonseca Pinto Tomaz Andrea De Rossi Rufato ${ }^{\text {II }}$ José Carlos Fachinello}

\section{RESUMO}

A physalis (Physalis peruviana) é uma pequena fruta com grandes potencialidades, que, associadas ao seu ciclo curto e às propriedades nutracêuticas, apresenta possibilidade de alto retorno econômico. $O$ objetivo deste trabalho foi avaliar o sistema de tutoramento e a época de transplante mais adequados para o crescimento e a produção de frutos de P. peruviana nas condições edafoclimáticas do sul do Rio Grande do Sul. O trabalho foi desenvolvido em Pelotas, RS, na safra de 2007/2008. O transplante de mudas de physalis foi realizado em duas épocas (época 1, 21/11/2007 e época 2 15/01/2008), sendo as plantas tutoradas em quatro sistemas de condução (sistema " $V$ " invertido, sistema triangular, sistema vertical com bambu e sistema vertical com fitilho), semelhantes aos utilizados na cultura do tomateiro. $O$ delineamento experimental adotado foi de blocos casualizados, com três repetições, sendo cada um representado por dez plantas. Os tratamentos formaram um fatorial $2 \times 4$ (épocas de transplante $x$ sistemas de tutoramento). As variáveis analisadas foram: incremento do comprimento e da área da seção do ramo principal, área da seção do ramo principal, produtividade e eficiência produtiva. Foi evidenciado que a primeira época de transplante associada aos sistemas de tutoramento " $V$ " invertido e triangular proporciona melhor desempenho agronômico das plantas de physalis.

Palavras-chave: Physalis peruviana, crescimento, produção, frutos, condução.

\section{ABSTRACT}

The cape-gooseberry (Physalis peruviana) is a small fruit with great potentialities that whether associated to its short cycle and nutraceutical properties it shows high economical return. The work aimed to evaluate the best training system and replant period to plant growth, production and fruit quality of P. peruviana under edaphoclimatic at conditions of southern Rio Grande do Sul. The trial was carried out in Pelotas, RS, in 2007/2008 crop. Transplanting seedlings capegooseberry was conducted in two seasons Plant replanting was done in two periods (period 1, 21/11/2007 and period 2, 15/ 01/2008). Plants were trained under four systems (inverted " $V$ " system, triangular system, vertical system using bamboo or vertical system using polypropylene cord), similarly to the tomato culture. Experimental design adopted was a complete randomized block in a $2 \times 4$ factorial (replant period $x$ training system) with three replications of ten plants each. The variables analyzed were: increment of length and section area of the main branch, section area of the main branch, yield and yield efficiency. It was evidenced that the first period of replant associated to the training systems inverted " $V$ " and triangular improved the agronomical performance of cape-gooseberry plants.

Key words: Physalis peruviana, growth, yield, fruits, training.

\section{INTRODUÇÃO}

A physalis (Physalis peruviana) é uma Solanaceae de grande valor nutricional e econômico que está sendo incorporada ao cultivo de pequenas frutas (CHAVES et al., 2005). Essa solanácea é consumida no Brasil como fruta exótica de preço bastante elevado, aproximadamente R\$35,00 o quilograma. Physalis, como é conhecida a espécie no

'Programa de Pós-graduação em Agronomia, área de concentração em Fruticultura de Clima Temperado, Departamento de Fitotecnia, Faculdade de Agronomia 'Eliseu Maciel' (FAEM), Universidade Federal de Pelotas (UFPEL), Campus Universitário Capão do Leão, CP 354, 96010-900, Pelotas, RS, Brasil. E-mail:claudialim@pop.com.br. *Autor para correspondência.

"Embrapa Uva e Vinho, Estação Experimental de Fruticultura Temperada, Vacaria, RS, Brasil. 
sul do país, caracteriza-se por produzir frutos açucarados e com um nível de ácido ascórbico muito elevado (36mg $100 \mathrm{~g}^{-1}$ polpa), ricos também em vitamina A (1730UI $100 \mathrm{~g}^{-1}$ de polpa), ferro (38mg $100 \mathrm{~g}^{-1} \mathrm{de}$ polpa) e fósforo (1,2mg $100 \mathrm{~g}^{-1}$ de polpa), além de serem atribuídas a esta espécie inúmeras propriedades medicinais (LIMA et al., 2009a).

A planta é considerada arbustiva e rústica, com ramificação muito densa, cujos ramos são decumbentes, necessitando de sistema de suporte (RUFATO et al., 2008). O tutoramento é obrigatório e o espaçamento adotado deve estar de acordo com o sistema de tutoramento empregado. O tipo de tutoramento requerido é escolhido em função da densidade de semeadura, da topografia do terreno, da disponibilidade de materiais e seus custos (LIMA et al., 2009b).

Em frutíferas que são tidas como anuais, e para as quais o principal método de propagação é por sementes, como a physalis, além do sistema de tutoramento, a época de semeadura e transplante são fatores importantes no conhecimento do manejo agronômico da cultura (PEIXOTO et al., 2000). Conforme NETO et al. (2001), as épocas de semeadura e transplante devem permitir a realização do cultivo no período mais favorável, em termos de oferta hídrica, de calor e luminosidade para o crescimento e desenvolvimento das plantas, assegurando, assim, menor risco aos produtores.

Pouco se sabe sobre o comportamento da physalis nas condições edafoclimáticas do sul do Rio Grande do Sul. Por isso, o conhecimento da época de transplante e tutoramento torna-se uma informação importante para determinar o momento mais adequado para iniciar o cultivo e obter melhores resultados produtivos e qualitativos. Além disso, não há, para esta frutífera, pesquisas que utilizem sistemas de tutoramento como os empregados na cultura do tomateiro (Solanum lycopersicon), e, ainda, relacionem estes fatores com épocas de transplante. Assim sendo, o objetivo deste estudo foi avaliar o sistema de tutoramento e a época de transplante mais adequadas para o crescimento, produção e qualidade de frutos de $\boldsymbol{P}$. peruviana nas condições edafoclimáticas de Pelotas, RS.

\section{MATERIAL E MÉTODOS}

O trabalho foi conduzido no período de agosto de 2007 a novembro de 2008 no Centro Agropecuário da Palma (CAP), pertencente à Faculdade de Agronomia Eliseu Maciel (FAEM), da Universidade Federal de Pelotas (UFPel), município de Pelotas, RS, latitude $31^{\circ} 52^{\prime} 00^{\prime \prime} \mathrm{S}$, longitude $52^{\circ} 21^{\prime} 24^{\prime \prime} \mathrm{W}$ e altitude
$13,24 \mathrm{~m}$. O clima da região caracteriza-se como temperado úmido com verões quentes, conforme a classificação de Köeppen, do tipo "Cfa". A região possui temperatura e precipitação médias anuais de $17,9^{\circ} \mathrm{C}$ e $1.500 \mathrm{~m}$, respectivamente (EAPel, 2009). Informações de temperatura e precipitação durante o período do experimento estão expostas na figura 1.

O solo onde foi implantado o experimento de physalis pertence à unidade de mapeamento Camaquã, sendo moderadamente profundo, com textura média no horizonte $\mathrm{A}$ e argilosa no $\mathrm{B}$, classificados como Argissolo Vermelho-Amarelo. A área possui relevo plano, com cobertura vegetal predominante de Bidens pilosa L. e Cyperus rotundus L. (ROSSI et al., 2007).

Para realização deste experimento, foram utilizadas mudas de physalis, oriundas de sementes, produzidas em bandejas de poliestireno expandido de 128 células preenchidas com substrato comercial $\left(\right.$ Plantmax $^{\circledR}$ ), em condições de telado. A semeadura foi realizada em duas épocas (04/09/2007 e 26/11/2007), realizou-se o transplante quando as plantas apresentavam aproximadamente $20 \mathrm{~cm}$ de altura e duas folhas verdadeiras.

O transplante foi realizado a campo em duas épocas diferentes: 21/11/2007 e 15/01/2008. A correção do solo foi realizada conforme análise do solo, expresso nas tabelas 1 e 2, para obter $\mathrm{pH}=6,0$, e a adubação foi realizada de acordo com a cultura do tomateiro, para uma expectativa de produtividade de 20 tha $^{-1}$ (RUFATO et al., 2008) (Tabela 3). O sistema de irrigação adotado foi por gotejamento. Não foram realizadas atividades de poda, desponte, desbrota e/ou raleio.

$\mathrm{Na}$ execução deste trabalho, não foi empregado o sistema de tutoramento livre, pois este não representa a realidade comercial e produtiva da espécie, além de não proporcionar o adequado crescimento das plantas de physalis (RUFATO et al., 2008). Foram utilizados quatro sistemas de tutoramento descritos abaixo. Para todos os sistemas, as hastes foram fixadas com fitilho. $\mathrm{O}$ espaçamento entre linhas foi $3,50 \mathrm{~m}$.

Tratamento 1 (T1) - sistema de tutoramento "V invertido"; neste sistema o bambu foi disposto obliquamente ao solo, formando um $\mathrm{V}$ invertido entre duas fileiras consecutivas de plantas. O espaçamento utilizado foi de $1,0 \times 1,0 \mathrm{~m}$ entre linhas e entre plantas, respectivamente. Tratamento 2 (T2) - sistema de tutoramento triangular; para se obter este tratamento, as fileiras ímpares foram iniciadas a $1,5 \mathrm{~m}$ do moirão principal, enquanto as fileiras pares iniciaram a $1,0 \mathrm{~m}$ deste, dando, assim, a conformação de um triângulo entre as plantas de fileiras contíguas. Para as demais 


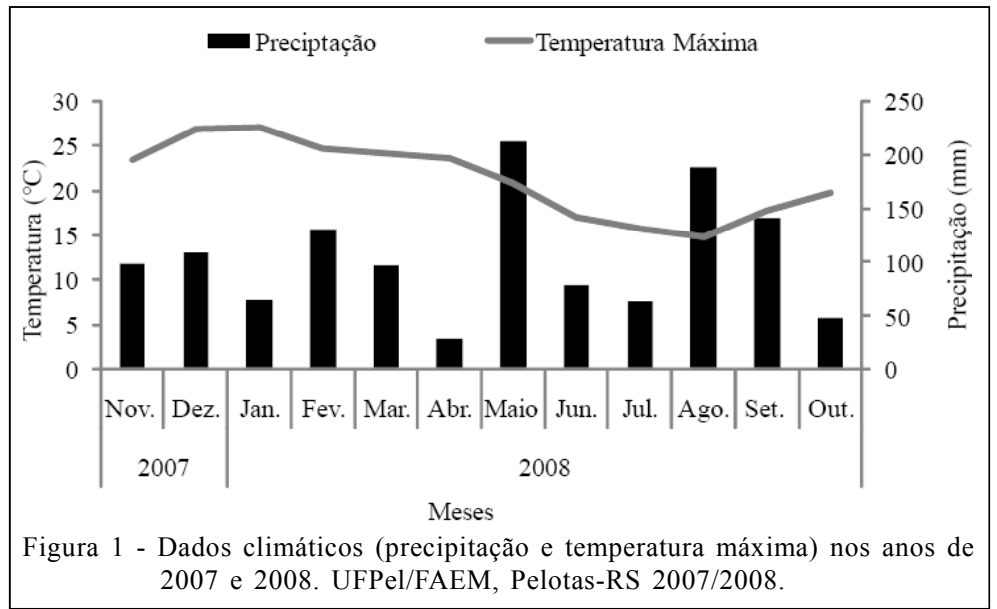

plantas das duas fileiras, o espaçamento utilizado foi de $1,0 \times 1,0 \mathrm{~m}$ entre e dentro das fileiras, respectivamente (Figura 2); Tratamento 3 (T3) - sistema de tutoramento vertical com bambu (varas de bambu); as plantas foram tutoradas perpendicularmente ao nível do solo, com tutores de bambu, com espaçamento de $1,0 \mathrm{~m}$ entre plantas; Tratamento 4 (T4) - sistema de tutoramento vertical com fitilho (fita de ráfia); neste sistema a planta foi tutorada por fitilhos presos a fio de arame horizontal e paralelo, o espaçamento foi de 1,0m entre plantas;

O crescimento das plantas foi avaliado medindo-se as seguintes variáveis: incremento do comprimento e do ramo principal, incremento do diâmetro do ramo principal e área da seção do ramo principal. As avaliações foram realizadas no início do experimento, no momento do transplante (21/11/2007 para a época 1 e 15/01/2008 para a época 2) e ao final do experimento, 300 dias após o transplante.

$\mathrm{O}$ incremento do comprimento do ramo principal $(\mathrm{cm})$ foi determinado a partir do nível do solo, com auxílio de uma fita métrica; obtido a partir da diferença entre as medidas realizadas no início e no término do experimento. $\mathrm{O}$ incremento da área da seção

Tabela 1 - Análise do solo de pré-plantio e interpretação dos resultados de acordo com as classes de fertilidade (CQFS-RS/SC, 2004). UFPel/FAEM. Pelotas-RS, 2008.

\begin{tabular}{|c|c|c|c|c|}
\hline $\mathrm{pH}$ água & Índice SMP & M.O. & Argila & $\mathrm{CTC}(\mathrm{pH} 7,0)$ \\
\hline & & \multicolumn{2}{|c|}{$(\%)$} & $\mathrm{cmol}_{\text {c. }} \mathrm{dm}^{-3}$ \\
\hline 5,3 & 6,50 & 1,4 & 13 & 6,5 \\
\hline \multicolumn{5}{|c|}{ Classe de fertilidade } \\
\hline B & - & B & - & M \\
\hline
\end{tabular}

B= Baixo, $\mathrm{M}=$ Médio. do ramo (haste) principal $\left(\mathrm{cm}^{2}\right)$ foi determinado a partir de $10 \mathrm{~cm}$ acima do nível do solo, por meio de paquímetro digital, medindo-se o diâmetro do ramo principal e, posteriormente, através da fórmula expressa abaixo, determinou-se a área da seção do ramo. $\mathrm{O}$ incremento da área da seção do ramo principal foi determinado pela diferença entre as medidas realizadas no início e no término do experimento.

\section{$\mathrm{A}=(\mathrm{p} \times(\mathrm{D} / 2) 2) / 100$}

Sendo: $A=$ área da seção do ramo $\left(\mathrm{cm}^{2}\right)$; $\mathrm{p}=3,1416$; $\mathrm{D}=$ diâmetro do ramo principal, em mm.

A área da seção do ramo principal $\left(\mathrm{cm}^{2}\right)$ foi obtida através de cálculo pela aplicação da fórmula citada acima. Para isto foram utilizadas as medidas finais de diâmetro do ramo principal.

A produtividade $\left(\mathrm{t} \mathrm{ha}^{-1}\right)$ foi obtida pelo somatório de todas as colheitas de março a setembro de 2008. Considerando o número total de plantas por hectare, para cada sistema de tutoramento, e a produção total por planta, foi calculada a produtividade estimada em toneladas por hectare. Para o sistema "V invertido" e triangular, foram consideradas 4440 plantas ha $^{-1}$, para os sistemas verticais com bambu e fitilho, 2857 plantas ha $^{-1}$.

A eficiência produtiva $\left(\mathrm{kg} \mathrm{cm}^{-1} \mathrm{e}\left(\mathrm{kg} \mathrm{cm}^{2}\right)^{-1}\right)$ foi obtida pela relação entre a produção total por planta e o comprimento final do ramo principal. Esta eficiência também foi determinada através da relação entre produção total por planta e área da seção do ramo, sendo expressa, respectivamente, por quilogramas de fruta por centímetros de comprimento de ramo e quilogramas de fruta por centímetros quadrados da área da seção do ramo.

O delineamento experimental adotado foi em blocos casualizados, com três repetições, cada uma representada por dez plantas. Os tratamentos formaram um fatorial $2 \times 4$, e o fator épocas de transplante 
Tabela 2 - Análise do solo de pré-plantio e interpretação dos resultados de acordo com as classes de fertilidade (CQFS-RS/SC, 2004). UFPel/FAEM. Pelotas-RS, 2008.

\begin{tabular}{|c|c|c|c|c|c|c|c|c|c|}
\hline $\mathrm{k}$ & $\mathrm{P}$ & $\mathrm{Ca}$ & $\mathrm{Mg}$ & $\mathrm{Al}$ & $\mathrm{Na}$ & $\mathrm{Cu}$ & $\mathrm{Mn}$ & $\mathrm{Zn}$ & $\mathrm{Fe}$ \\
\hline \multicolumn{2}{|c|}{-------- $\left(\mathrm{mg} \mathrm{dm}^{3}\right)--------$} & \multicolumn{3}{|c|}{ 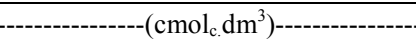 } & \multicolumn{5}{|c|}{ 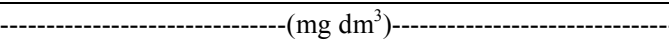 } \\
\hline 94 & 14,1 & 2,5 & 1,3 & 0,2 & 7 & 2,1 & 20 & 1,6 & 9 \\
\hline A & M & M & A & - & - & A & A & A & A \\
\hline
\end{tabular}

$\mathrm{A}=$ Alto, $\mathrm{M}=$ Médio

apresentou dois níveis: época $1(21 / 11 / 2007)$ e época 2 (15/01/2008), e o fator sistema de tutoramento, quatro níveis: sistema "V" invertido (T1), sistema triangular (T2), sistema vertical com bambu (T3) e sistema vertical com fitilho (T4).

A análise estatística dos dados foi realizada por meio da análise de variação pelo teste $\mathrm{F}$ e, quando o efeito dos fatores e da interação entre estes foi significativo, realizou-se teste de comparação de médias (Tukey) ao nível de $5 \%$ de probabilidade de erro.

\section{RESULTADOS E DISCUSSÃO}

Houve interação significativa entre os fatores épocas de transplante e sistemas de tutoramento para todas as variáveis de resposta analisadas. Como as informações a respeito de tutoramento de physalis são escassas, principalmente quando associamos a outras formas de tutoramento de plantas, faz-se necessário relacionar os resultados com outras espécies de hábito de crescimento semelhante à physalis, como é o caso do tomateiro. Assim, neste trabalho, também foram utilizadas referências que continham resultados e explicações a respeito da cultura do tomateiro tutorado.

Para a variável resposta incremento do comprimento do ramo principal, os maiores valores foram obtidos na associação da primeira época de

Tabela 3 - Principais fertilizantes e adubos químicos utilizados no experimento de Physalis peruviana, adubação realizada de acordo com a cultura do tomateiro. UFPel/FAEM, Pelotas-RS 2007/2008.

\begin{tabular}{lc}
\hline Fertilizantes e adubos químicos utilizados & Quantidade $\left(\mathrm{kg} \mathrm{ha}^{-1}\right)$ \\
\hline Ureia & 45,45 \\
Superfosfato triplo & 270,26 \\
Cloreto de potássio & 68,96 \\
\hline
\end{tabular}

*Aplicação de $2 / 3$ da dose no sulco aproximadamente duas semanas antes do plantio e o restante 15 a 20 dias após o transplante das mudas. transplante com sistema de tutoramento "V" invertido. A primeira época de transplante resultou nas maiores médias para todos os sistemas de tutoramento. Os sistemas de tutoramento verticais com bambu e com fitilho proporcionaram o menor incremento do comprimento dos ramos principais (Tabela 4). Estes resultados são contrários aos obtidos por MARIN et al. (2005). Estes autores, utilizando os mesmos sistemas de tutoramento, não observaram diferenças significativas no incremento do ramo principal em plantas de tomateiro tutoradas, mas, sim, na produção e qualidade dos frutos.

De acordo com SZPINIAK (2000), os sistemas "V" invertido e triangular proporcionam às plantas de tomateiro menor distribuição da radiação solar, e, deste modo, favorecem o crescimento em comprimento dos ramos principais, devido à maior intensidade de seiva para as partes mais altas e iluminadas da planta, informações semelhantes às observadas neste experimento.

As plantas oriundas da primeira época foram transplantadas em novembro, sendo submetidas a um período maior de temperaturas médias mensais elevadas, já as da segunda época, foram transplantadas em janeiro, quando começa haver redução das temperaturas médias mensais. Conforme ESCOBAR (2000), plantas de physalis recém transplantadas possuem seu incremento favorecido com temperaturas próximas de $21^{\circ} \mathrm{C}$.

O incremento da área da seção do ramo principal foi superior nas plantas oriundas da primeira época de transplante para todos os sistemas de tutoramento, com exceção ao vertical com bambu. $\mathrm{Na}$ primeira época de transplante, o maior crescimento foi de $3,13 \mathrm{~cm}^{2}$ no sistema "V" invertido, e o menor foi de $1,53 \mathrm{~cm}^{2}$ no sistema vertical com bambu. Para a segunda época de transplante, as maiores médias também foram obtidas no sistema "V" invertido $\left(2,56 \mathrm{~cm}^{2}\right)$, já o menor incremento de área foi verificado no sistema vertical com fitilho $\left(1,27 \mathrm{~cm}^{2}\right)$.

Os sistemas de tutoramento "V" invertido e vertical com fitilho em plantas de tomateiro 


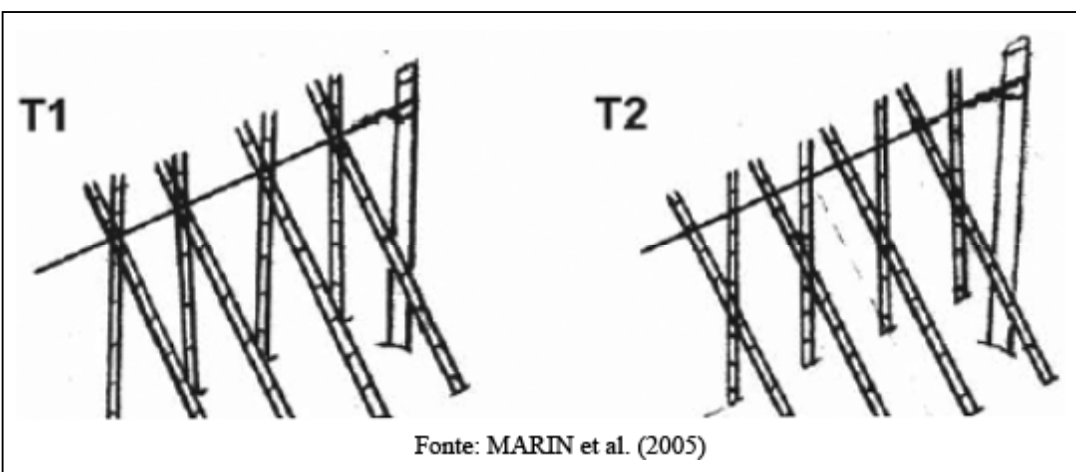

Figura 2 - Esquema ilustrativo do sistema de condução de plantas de physalis. UFPel/ FAEM, Pelotas,RS, 2008. * (T1) "V"invertido e (T2) triangular.

proporcionaram maior incremento de área do caule, devido à curvatura formada na base do caule no sistema vertical, pois este tipo de sistema, mesmo que adequadamente manejado, sobrecarrega a base da planta, ocasionando má distribuição de seiva nos ramos (SILVA et al., 2008). Entretanto, as respostas encontradas por SILVA et al. (2008) foram influenciadas pelo ponto de avaliação, que foi na curvatura do caule, diferente do realizado neste experimento, no qual as medições foram realizadas $10 \mathrm{~cm}$ acima do nível do solo, (acima da curvatura do ramo). Segundo GOMEZ (2000), plantas de physalis são classificadas como vigorosas quando, ao final do ciclo (290 dias após o transplante), apresentam incremento de aproximadamente $2 \mathrm{~cm}$ e, de baixo vigor, quando o incremento é inferior a $1 \mathrm{~cm}$.

Assim como para a variável anterior, o efeito da época de transplante pode estar relacionado com a temperatura, pois, conforme ANTONIOLLI \& CASTRO (2008), o crescimento em diâmetro do caule é um indicador sensível ao efeito de diferentes temperaturas na planta; a mudança de temperatura altera imediatamente o crescimento do caule de tomateiro. Segundo estes autores, foi observado que, em temperatura de $26,5^{\circ} \mathrm{C}$, o índice de crescimento do caule atingiu $23 \mathrm{~mm} \mathrm{dia}^{-1}$, estabilizando-se quando as plantas atingiram $30 \mathrm{~cm}$ de altura.

Observa-se, na tabela 4, que a maior área da seção do ramo foi obtida na primeira época de transplante, combinado com o sistema de tutoramento "V" invertido. Neste mesmo sistema, também foram verificados valores superiores para a segunda data de transplante. Os menores resultados foram encontrados para a segunda data de transplante nos sistemas verticais. Este comportamento também foi evidenciado para o crescimento do diâmetro dos ramos, indicando que as plantas de physalis, quando submetidas a condições de queda de temperaturas durante seu crescimento, associado ao manejo com sistemas de tutoramento vertical, tornam-se menos vigorosas. De acordo com ANTONIOLLI \& CASTRO (2008), o crescimento do tomateiro é influenciado pela temperatura, e plantas transplantadas na primavera dispõem de um maior período para o aumento de área (área foliar, diâmetro, comprimento de ramos) e, consequentemente, apresentam uma área maior que aquelas transplantadas no verão.

Informações a respeito do desenvolvimento e crescimento de plantas como a physalis, que possuem crescimento rápido, são muito importantes, pois, conforme PEREIRA (2008), o crescimento das espécies se modifica em função do ambiente, genótipo e das práticas de manejo. Além disso, estes estudos possibilitam a implementação de estratégias de manejo visando à obtenção de maiores rendimentos.

Os maiores valores de produtividade foram encontrados no sistema "V" invertido, associado com a primeira época de transplante (Tabela 4). De forma geral, apenas os sistemas vertical e triangular, associados à segunda época de transplante, resultaram em valores inferiores ao esperado para a cultura, que, segundo BRITO (2002), chega a atingir médias de 10 a $15 \mathrm{tha}^{-1}$. A CORPORACIÓN COLOMBIANA INTERNACIONAL (2000) afirma que a produtividade média está entre $15 \mathrm{a} 20 \mathrm{t} \mathrm{ha}^{-1}$. Conforme NEREMBERG (2000), no Equador, a produção não excede as $12 \mathrm{t} \mathrm{ha}^{-1}$ e, segundo RODRIGUEZ (1995), na Nova Zelândia, a produção média gira em torno de 8 a $12 \mathrm{t} \mathrm{ha}{ }^{-1}$. Na Alemanha, a produtividade experimental estaria entre 5 a 9t ha-1 (OBRECHT, 1993). No Brasil, ainda não há dados oficiais de produtividade de physalis. Em áreas experimentais em Lages, $\mathrm{SC}$, foram verificados valores entre 2 a 8,67 ha $^{-1}$ (BRIGHENTI et al., 2008).

$\mathrm{Na}$ tabela 4, observa-se a eficiência produtiva de plantas de physalis, considerando o comprimento do ramo principal. A primeira época de transplante, combinada com os sistemas de 
Tabela 4 - Valores médios de incremento no comprimento, incremento da área da seção do ramo principal, área da seção do ramo principal, produtividade e eficiência produtiva (comprimento e área) de plantas Physalis peruviana, em função de quatro sistemas de tutoramento e duas datas de transplante. UFPel/FAEM, Pelotas-RS 2007/2008.

\begin{tabular}{|c|c|c|c|}
\hline \multirow{2}{*}{ Variáveis } & \multirow{2}{*}{ Sistemas de tutoramento } & \multicolumn{2}{|c|}{ 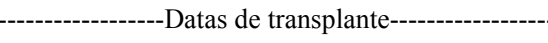 } \\
\hline & & $1(21 / 11 / 2007)$ & $2(15 / 01 / 2008)$ \\
\hline \multirow{4}{*}{$\begin{array}{l}\text { Incremento do comprimento do ramo } \\
\text { principal }(\mathrm{cm})\end{array}$} & "V" invertido & $77,44 \mathrm{aA}$ & $51,35 \mathrm{aB}$ \\
\hline & Triangular & $62,10 \mathrm{bA}$ & $42,80 \mathrm{bB}$ \\
\hline & Vertical com bambu & $52,38 \mathrm{cA}$ & $36,69 \mathrm{cB}$ \\
\hline & Vertical com fitilho & $49,88 \mathrm{dA}$ & $32,58 \mathrm{~dB}$ \\
\hline \multirow{3}{*}{$\begin{array}{l}\text { Média Geral } \\
\text { CV }(\%)\end{array}$} & & \multicolumn{2}{|c|}{50,55} \\
\hline & & \multicolumn{2}{|c|}{2,68} \\
\hline & "V" invertido & $3,13 \mathrm{aA}$ & $2,56 \mathrm{aB}$ \\
\hline \multirow{3}{*}{$\begin{array}{l}\text { Incremento da área da seção do ramo } \\
\text { principal }\left(\mathrm{cm}^{2}\right)\end{array}$} & Triangular & $2,28 \mathrm{bA}$ & $2,04 \mathrm{bB}$ \\
\hline & Vertical com bambu & $1,53 \mathrm{dA}$ & $1,34 \mathrm{cA}$ \\
\hline & Vertical com fitilho & $1,68 \mathrm{cA}$ & $1,27 \mathrm{cB}$ \\
\hline \multirow{2}{*}{\multicolumn{2}{|c|}{$\begin{array}{l}\text { Média Geral } \\
\text { CV }(\%)\end{array}$}} & \multicolumn{2}{|c|}{1,97} \\
\hline & & \multicolumn{2}{|c|}{15,60} \\
\hline \multirow{4}{*}{ Área da seção do ramo principal $\left(\mathrm{cm}^{2}\right)$} & "V" invertido & $3,00 \mathrm{aA}$ & $2,69 \mathrm{aB}$ \\
\hline & Triangular & $2,50 \mathrm{bA}$ & $2,13 \mathrm{bB}$ \\
\hline & Vertical com bambu & $1,77 \mathrm{cA}$ & $1,40 \mathrm{cB}$ \\
\hline & Vertical com fitilho & $1,60 \mathrm{dA}$ & $1,34 \mathrm{~dB}$ \\
\hline \multirow{3}{*}{$\begin{array}{l}\text { Média Geral } \\
\text { CV }(\%)\end{array}$} & & 2,05 & \\
\hline & & 1,72 & \\
\hline & "V" invertido & $14,36 \mathrm{aA}$ & $9,72 \mathrm{aB}$ \\
\hline \multirow{3}{*}{ Produtividade $\left(\mathrm{t} \mathrm{ha}^{-1}\right)$} & Triangular & $12,53 \mathrm{bA}$ & $8,54 \mathrm{bB}$ \\
\hline & Vertical com bambu & $7,22 \mathrm{cA}$ & $4,91 \mathrm{cB}$ \\
\hline & Vertical com fitilho & $6,90 \mathrm{dA}$ & $4,53 \mathrm{cB}$ \\
\hline \multirow{3}{*}{$\begin{array}{l}\text { Média Geral } \\
\text { CV }(\%)\end{array}$} & & 8,54 & \\
\hline & & 2,52 & \\
\hline & "V" invertido & $0,06 \mathrm{aA}$ & $0,04 \mathrm{aB}$ \\
\hline \multirow{3}{*}{ Comprimento do ramo principal $\left(\mathrm{Kgcm}^{-1}\right)$} & Triangular & $0,06 \mathrm{aA}$ & $0,03 \mathrm{aB}$ \\
\hline & Vertical com bambu & $0,05 \mathrm{aA}$ & $0,02 \mathrm{bB}$ \\
\hline & Vertical com fitilho & $0,03 \mathrm{bA}$ & $0,02 \mathrm{bB}$ \\
\hline \multirow{3}{*}{$\begin{array}{l}\text { Média Geral } \\
\text { CV }(\%)\end{array}$} & & 0,06 & \\
\hline & & 7,95 & \\
\hline & "V" invertido & $1,07 \mathrm{dA}$ & $0,81 \mathrm{~dB}$ \\
\hline \multirow{3}{*}{ Área da seção do ramo $\left(\mathrm{Kgcm}^{2}\right)^{-1}$} & Triangular & $1,12 \mathrm{cA}$ & $0,90 \mathrm{cB}$ \\
\hline & Vertical com bambu & $1,43 \mathrm{bA}$ & $1,22 \mathrm{aB}$ \\
\hline & Vertical com fitilho & $1,50 \mathrm{aA}$ & $1,17 \mathrm{bB}$ \\
\hline \multirow{2}{*}{\multicolumn{2}{|c|}{$\begin{array}{l}\text { Média Geral } \\
\text { CV }(\%)\end{array}$}} & 2,23 & \\
\hline & & 4,43 & \\
\hline
\end{tabular}

*Médias não seguidas pela mesma letra minúscula na coluna e maiúscula na linha diferem entre si pelo teste de Tukey $(\mathrm{P}=0,05)$.

* Para todas as variáveis: as avaliações foram realizadas no início do experimento, no momento do transplante (21/11/2007 para a época 1 e 15/01/2008 para a época 2) e ao final do experimento, 300 dias após o transplante.

tutoramento "V" invertido, triangular e vertical com bambu se destaca dos demais com uma eficiência produtiva superior a $0,04 \mathrm{~kg} \mathrm{~cm}^{-1}$, já na segunda época de transplante, em todos os sistemas de condução, houve a menor eficiência, com valores iguais ou inferiores a $0,04 \mathrm{~kg} \mathrm{~cm}^{-1}$. Nesta época de transplante, $15 / 01 / 2008$, a maior média foi verificada nos sistema "V" invertido $\left(0,04 \mathrm{~kg} \mathrm{~cm}^{-1}\right)$, entretanto, só diferiu dos valores obtidos nos sistema verticais com bambu e fitilho, nos quais foram verificados os menores valores, 0,03 e $0,02 \mathrm{~kg} \mathrm{~cm}^{-1}$, respectivamente.

No caso da eficiência produtiva expressa em quilogramas de fruta por centímetros quadrados da área da seção do ramo, pode-se observar que os valores modificam consideravelmente. Os resultados obtidos em ambas as épocas de transplante demonstram que 
sistemas de tutoramento que resultaram em plantas mais vigorosas (sistema "V" invertido e triangular), apresentaram resultados de eficiência produtiva inferior. Inicialmente, o esperado para as variáveis relacionadas com a produção, produtividade estimada e eficiência produtiva, era que os valores mais representativos fossem obtidos nos sistemas verticais associados à primeira data de transplante. Isso ocorre devido ao fato destes sistemas serem considerados os mais produtivos na cultura do tomateiro (cerca de $30 \%$ superior) e apresentarem a característica de facilitar o manejo bem como promover melhor aeração e penetração de luz nas plantas (SANTOS et al., 1999; WAMSER et al., 2006; SILVA et al., 2008). Além disso, as plantas transplantadas em novembro (primeira época de transplante) foram submetidas a temperaturas próximas às ideais ao cultivo $\left(25^{\circ} \mathrm{C}\right)$ e a um maior período livre de geadas.

Entretanto, as respostas verificadas para a produção de frutos de physalis, no que se refere aos sistemas de tutoramento, não estiveram de acordo com o esperado, e podem ser justificadas, através das observações realizadas por COSTA et al. (2005). Estes autores, avaliando diferentes sistemas de condução em maxixe-do-reino [Cyclanthera pedata L. (Schrad.)], constataram que o sistema de tutoramento com fitilho ocasiona má distribuição dos ramos e menor produção, devido ao maior contato das ramificações com o solo. Além disso, conforme AZEVEDO (2006), nos sistemas verticais, as plantas naturalmente formam uma maior curvatura na base do caule, o que dificulta seu crescimento e desenvolvimento, resultando em menores produções.

\section{CONCLUSÃO}

A primeira data de transplante de mudas (21/ $11 / 2007)$, associada aos sistemas de tutoramento "V" invertido e triangular, é mais adequada para o plantio de physalis, na região de Pelotas, $\mathrm{RS}$, pois proporciona melhor crescimento e produtividade.

\section{REFERÊNCIAS}

ANTONIOLLI, L.R.; CASTRO, P.R.C. Tomateiro. In: CASTRO, P.R.C.et al. Manual de fisiologia vegetal: fisiologia de cultivos. Piracicaba: Agronômica Ceres, 2008. p.748-762.

AZEVEDO, V.F. de. Produção orgânica de tomateiro tipo "Cereja": comparação entre cultivares, espaçamentos e sistemas de condução da cultura. 2006. 84f. Dissertação (Mestrado em Produção Vegetal) - Programa de pós-graduação em Fitotecnia, Universidade Federal Rural do Rio de Janeiro, RJ.
BRIGHENTI, A.F. et al. Cultura da physalis no planalto catarinense e a influência de sistemas de condução na qualidade dos frutos. In: CONGRESSO BRASILEIRO DE FRUTICULTURA, 20., 2008, Vitória, ES. Anais... Vitória: SBF/UFES, 2008. CD/ROOM.

BRITO, D.F.M. Producción de Uvilla para exportación. Quito, Equador: Fundación Ecuatoriana de Tecnologia Apropiada (FEDETA), 2002. 10p.

CHAVES, A.C. et al. Estabelecimento e multiplicação in vitro de Physalis peruviana L. Revista Ciência Agrotécnica, Lavras, v.29, n.6, p.1281-1287, 2005. Disponível em: <http://www.scielo.br/ scielo.php?pid=S010384782008000700040\&script=sci_arttext. $>$. Acesso em: 20 out. 2008. doi: 10.1590/S0103-84782008000700040.

COSTA, C.A. et al. Produção do maxixe-do-reino em função do sistema de tutoramento e do espaçamento. Horticultura Brasileira, Brasília, v.23, n.1, p. 28-31, 2005. Disponível em: $<$ http://www.scielo.br/scielo.php?script=sci_arttext\&pid=S010205362005000100006> Acesso em: 21 out. 2008. doi: 10.1590/ S0102-05362005000100006.

CORPORACIÓN COLOMBIANA INTERNACIONAL (CORPOICA). EI mercado de la Uchuva. Bogotá: CCI Exótica, 2000. V.3. 5p. (Boletim Técnico, 4).

EAPel- Estação Agroclimatólogica de Pelotas. Disponível em: $<$ http://www.cpact.embrapa.br/agromet/ estacao/index.html >. On line. Acesso em: 20 jan. 2009.

ESCOBAR, O.C. Manejo agronómico de materiales de uchuva (Physalis peruviana) em la region de Tierradentro, Departamento del Cauca. Popayon Cauca, Colômbia: Corporación Colombiana de Investigación Agropecuaria (CORPOICA), Reginonal 5, 2000. 22p. (Boletim Técnico, 31).

GOMEZ, R.R. Efectos de la conducion em uchuva. 2000. 113f. Monografia (Graduação em Agronomia) - Escuela de Agronomia, Pontifícia Universidad Javeriana.

LIMA, C.S.M. et al. Características físico-químicas de physalis em diferentes colorações do cálice e sistemas de condução. Revista Brasileira de Fruticultura, Jaboticabal, v.31, n.4, p.1061-1068, 2009a. Disponível em: <http://www.scielo.br/ s c i e 1 o.p h p ? p i d = S 0100029452000900004 $00020 \&$ script $=$ sci_abstract\&tlng $=\mathrm{pt}>$. Acesso em: 20 maio, 2010. doi: 10.1590/S0100-29452009000400020.

LIMA, C.S.M. et al. Custos de implantação e condução de pomar de Physalis na região sul do estado do Rio Grande do Sul. Revista Ceres, Viçosa, v.56, n.5, p.551-561, 2009b. Disponível em: < www.ceres.ufv.br/CERES/revistas/V56N005P18608.pdf ->. Acesso em: 14 jan. 2010.

MARIN, B.G. et al. Sistemas de tutoramento e condução do tomateiro visando produção de frutos para consumo in natura. Horticultura Brasileira, Brasília, v.23, p.951-955, 2005. Disponível em: <www.scielo.br/pdf/hb/v23n4/a18v23n4.pdf>. Acesso em: 13 set. 2009. doi: 10.1590/S010205362005000400018 .

NAIKA, S. et al. A cultura do tomate produção, processamento e comercialização. Wageningen: Fundação Agromisa e CTA, 2006. 104p. 
NEREMBERG, F.A. Comportamiento agronomico de Physalis peruviana $L$. proviniente de semillas y estabelecida em distintas conduccion. 2000. 112f. Tese (Doutorado em Agronomia) - Facultad Ciencias Agrarias, Universidad Central del Equador.

NETO, M. da S. et al. Zoneamento agroecológico e época de semeadura para a mamoneira na região Nordeste do Brasil. Revista Brasileira de Agrometeorologia, Passo Fundo, v.9, n.3, p.551-556, 2001. Disponível em: <triticale. cnpt.embrapa.br/pesquisa/agromet/pdf/revista/cap20.pdf $>$. Acesso em: 14 mar.2009.

OBRECHT, A.S. Estudio fenologico de uvilla (Physalis peruviana L.). 1993. 71f. Tese (Doutorado em Agronomia) Faculad Ciencias Agricolas e Florestais, Univesidad Chile.

PEIXOTO, G.P. et al. Épocas de semeadura e densidade de plantas de soja: I. Componentes de produção e rendimento de grãos. Scientia Agrícola, Piracicaba, v.57, n.1, p.47-61, 2000. Disponível em: $<$ http:/www.scielo.br/scielo.php?script=sci_arttext\&pid=S010390162000000100015>. Acesso em: 14 jan. 2009. doi: 10.1590/ S0103-90162000000100015.

PEREIRA, I. dos S. Adubação de pré-plantio no crescimento, produção e qualidade da amoreira-preta (Rubus sp.). 2008. 102f. Dissertação (Mestrado em Agronomia) - Programa de pós-graduação em Agronomia, Universidade Federal de Pelotas, RS.

RODRIGUEZ, C.D.L. Efectos de la conduccion y fertilizacion sobre la producion, crecimiento y desarrollo en uvilla. 1995. 76f. Monografia (Graduação em Agronomia) - Santiago: UCHILE/FCAF.
ROSSI, A. de et al. Diferentes manejos da cobertura vegetal de aveia-preta em pomar no Sul do Brasil. Bragantia, Campinas, v.66, n.3, p.457-463, 2007. Disponível em: <http:// www.scielo.br/scielo.php? script $=$ sci_arttext\&pid $=$ S000687052007000300012>. Acesso em: 21 maio, 2010. doi: $10.1590 / \mathrm{S} 0006-87052007000300012$

RUFATO, L. et al. Aspectos técnicos da cultura da physalis. Lages: CAV/UDESC; Pelotas: UFPel, 2008. 100p.

SANTOS, H.S et al. Avaliação de sistemas de condução em relação à severidade de doenças e à produção do tomateiro. Acta Scientiarum, Maringá, v.21, p.453-457, 1999. Disponível em: <http://periodicos.uem.br/ojs/index.php/ ActaSciAgron/article/viewArticle/4257>. Acesso em: 13 jan. 2009. ISSN 1415-6814. ISSN 1679-9275 (print) and ISSN 1807-8621 (on-line)

SILVA, A. et al. Efeito de dosagens de adubação no comportamento agronômico de tomateiro, sob dois sistemas de tutoramento. In: CONGRESSO BRASILEIRO DE OLERICUlTURA, 48., 2008, Maringá. Anais... Maringá: Horticultura Brasileira, 2008. CD/ROOM.

SZPINIAK, M. O cultivo do tomate, fisiologia. Barcelona: Polyasack, 2000. 7p.

WAMSER, A.F. et al. Produção do tomateiro em função dos métodos de condução e de tutoramento de plantas. In: CONGRESSO BRASILEIRO DE OLERICULTURA, 46., 2006, Goiânia. Anais... Goiânia: Horticultura Brasileira, 2006. CD/ ROOM. 